de Ricardo Acevedo surge de sus esfuerzos por instalar una marca local en la música para guitarra, que lo conecta además a las fuentes de la música popular latinoamericana en las que la guitarra ha encontrado un espacio que ya se define como propio.

Mauricio Valdebenito Cifuentes Facultad de Artes,

Universidad de Chile, Chile mvalde67@gmail.com

\title{
Ernesto Guarda Carrasco
}

\section{(La Unión, 8 de agosto, 1933-18 de febrero, 2014)}

El sur de Chile ha perdido a uno de sus músicos señeros con la partida de Ernesto Guarda este año 2014. Maestro de generaciones, profesor universitario y escolar, fundador de diversas instituciones y un apasionado de la música chilena, fue central en la vida musical del sur entero durante la segunda mitad del siglo XX y no será olvidado. Esta pequeña reseña, profundamente personal, la escribo a la distancia, desde Inglaterra, en recuerdo de un gran músico de mi tierra.

Conocí a Ernesto Guarda, como tantos otros estudiantes valdivianos, siendo recibido en su casa con los brazos abiertos, cuando tenía como dieciséis años y mi única educación musical había sido la escolar. Ernesto era un hombre enorme y una sonrisa penetrante, cálida, que parecía encontrarse con uno desde el primer minuto. Su boina era lo único que podía asimilar a un músico bohemio, pues Ernesto era trabajador y constante como pocos, un caballero a la antigua, para quien la ética y el deber cívico hacia el otro eran máximas centrales en la vida, que no podían ser dejadas de lado. Ernesto me dio clases tres años voluntariamente, cada semana o cada dos, obligándome a hacer ejercicios constantes, probando mis conocimientos en armonía, contrapunto, orquestación y arreglos corales.

Una de sus mayores pasiones era la musicalidad en la poesía de Gabriela Mistral y como sus palabras podían ser transformadas una y otra vez en música. Escribir un libro sobre la música en Gabriela Mistral y a partir de ella, fue uno de los proyectos que quedaron inconclusos. La primera tarea que me dio cuando lo visité fue componer un Lied sobre uno de los poemas de Tala, el cual contrastó para mí con varios modelos de otros compositores chilenos. Ernesto compuso una enorme cantidad de piezas corales que han sido parte del repertorio de diversos grupos en Chile, han sido grabadas en más de algún disco e interpretadas en particular en el sur de Chile y el de Argentina.

Ernesto era, cabe decirlo, un hombre del sur. Nació en La Unión y estudió en la ya mítica Escuela Normal de Valdivia "Camilo Henríquez”. Egresó luego de la Escuela Normal Superior "José Abelardo Núñez" en Santiago, estudió contrabajo en la Universidad de Chile y egresó, en un ir y venir de la capital, como Profesor de Educación Musical en la Universidad Austral de Chile, con distinción máxima. En Santiago tomó clases privadas de composición con Enrique Soro, quien lo recibió amablemente en su casa incontables veces, casi siempre sin cobrarle. Pero fue en Valdivia donde se instaló y trabajó en varias escuelas primarias de la ciudad, asesorando en temas culturales y musicales al Ministerio de Educación Pública de entonces, para luego enseñar a incontables estudiantes en los Institutos Comercial y Alemán de Valdivia.

Fue miembro de la Asociación Nacional de Compositores de Chile desde 1977 y siempre mantuvo una relación estrecha con la composición musical desde el sur de Chile. Ernesto experimentó con algunos de los vaivenes de la música contemporánea en su obra Laberintofonía para cuarteto de cuerdas, la que fuera estrenada en el XIII Festival de Música Chilena, en enero de 1998 en la Universidad de Chile, o en Transparencias aleatorias para piano de 1996. No obstante, su corazón estaba asentado en el repertorio coral y, por lo tanto, en una capacidad infinita para transformar la armonía a varias partes en su música y la de otros. Dirigió incontables coros en el sur y arregló para ellos una gran cantidad de música, lo que llevó a que prácticamente cada nueva institución en la provincia de Valdivia 
le encargara a él un himno coral. Catorce himnos locales son de su completa autoría y otros muchos fueron arreglados o finalizados por él. De hecho, tanto los himnos del Instituto Alemán, Instituto Inmaculada Concepción y aquel de la Universidad Austral de Chile son cantados hoy en la versión de Ernesto Guarda. Esta relación personal y profunda a través de la música con la ciudad de Valdivia era, por lejos, uno de sus mayores orgullos.

Fue miembro de varias orquestas, en Santiago y Valdivia, y esta relación quedó desplegada en su carrera posterior. Además de dirigir por varios años el curso de Práctica Instrumental de la Facultad de Bellas Artes de la Universidad Austral de Chile, fue también cofundador junto a Sigfried Erber de la orquesta de esta universidad. Escribió un libro sobre la vida orquestal en Chile, editado a nivel local a comienzos del presente siglo, el cual es único en su tipo. El año 2012 tuve la oportunidad de reescribir este trabajo, junto a don Ernesto, valorando con él la vida de innumerables músicos de orquesta del país, uno de sus grandes anhelos. Este trabajo, que nació de una relación que no se interrumpió durante toda mi estadía en Santiago, es uno de los grandes tesoros que guardo de su persona, pues en ningún lugar queda mejor reflejado el interés de Ernesto por las personas, por el músico de cada día, por un defender y reconocer a todos. Su relación con el quehacer musical de Chile la puso en práctica también en la Sociedad de Amigos del Arte de Valdivia.

El aporte de don Ernesto superó con creces el espacio musical, siendo un constante amigo y apoyo para cientos de personas. Su preocupación por aquellas personas con algún tipo de discapacidad se vio reflejada en muchos actos de importancia. No menor entre ellos fue la fundación de la Escuela Diferencial de Discapacitados Visuales “Ann Sullivan”. Quizás su proyecto fundacional más relevante fue, sin embargo, lo que hoy es el Colegio Juan Sebastián Bach de Valdivia, inaugurado como escuela artística hace más de cuarenta años y cuyo auditorio lleva el nombre de Ernesto Guarda Carrasco. Ya por aquel acto fundacional Ernesto Guarda recibió el premio de Extensión Cultural y Artística de Valdivia (1975) y el premio a los "Mejores de Chile" de la Secretaría Nacional de la Juventud (1977), además de ser reconocido en 1985 como el "Profesor más representativo de la zona sur de Chile" por el Ministerio de Educación. En 1996 en Bariloche se le entregó un premio por su aporte a la hermandad entre ambos países. En los últimos años le empezaron a llegar los reconocimientos a él con cada vez mayor frecuencia, incluyendo su incorporación como miembro de la Academia Chilena de Bellas Artes y el premio a la trayectoria el año 2012 por parte de la Ilustre Municipalidad de Valdivia, en reconocimiento a su enorme aporte a la ciudad.

Como tantos otros músicos del sur, a Ernesto le debo mucho, incluyendo el animarme y apoyarme en todo momento a seguir una carrera en la música. Siempre respaldó e impulsó el talento de todos y no me imagino una palabra negativa que se podría decir sobre una persona que siempre puso la integridad y la ética como las más altas aspiraciones, sólo superadas, quizás, por el amor y la música. Para el sur de Chile, la pérdida de Ernesto Guarda se sentirá por largo tiempo y, sin duda, son muchos los que hoy, en Chile y en el extranjero, agradecen sus constantes enseñanzas, preocupaciones y consejos, junto a un cariño explícito por su tierra y por su gente.

José Manuel Izquierdo König Gates Cambridge Scholar, University of Cambridge Premio ProArte Ilustre Municipalidad de Valdivia Izquierdokonig@gmail.com 